\title{
A publicação científica sobre desenho arquitetônico análise bibliométrica da revista Educação Gráfica
}

\section{João Augusto Moreira*, Daniel de Carvalho Moreira.}

\section{Resumo}

A pesquisa realiza uma análise bibliométrica dos artigos publicados entre 2014 e 2016 na revista Educação Gráfica sobre o desenho arquitetônico, com base em métodos bibliométricos e de co-citação.

\section{Palavras-chave:}

Desenho arquitetônico; Bibliometria; Revista Educação Gráfica.

\section{Introdução}

A bibliometria é um procedimento de análise quantitativa da literatura científica e é definida como a técnica de avaliação de fluxos de informação, da comunicação acadêmica e da difusão de conhecimento científico, incluindo estudos dos aspectos da produção, disseminação e uso da informação. Um dos principais modelos de análise bibliométrica é a análise de citações, que procura identificar padrões de conexão e de relação entre documentos citados na literatura científica em uma determinada área.

\section{Resultados e Discussão}

O projeto organizou um corpo de dados bibliográficos das produções científicas sobre desenho arquitetônico publicadas na revista Educação Gráfica permitindo a análise bibliométrica dos trabalhos levantados. Para o desenvolvimento do projeto, foi definido um procedimento organizacional dos dados, armazenandoos em uma planilha da ferramenta Google Planilhas através da função Import XML. Essa função permite a extração de dados de páginas $h t m l$ por meio de um método conhecido como Scraping.

Além disso, foi realizada a organização de um banco de dados para armazenar as referências bibliográficas dos artigos, utilizando uma extensão para o navegador Mozilla Firefox chamada Zotero. Posteriormente foi feita a formatação dos dados e a preparação para análise nos softwares bibliométricos CitNetExplorer e VOSviewer.

Figura 1. Planilha em Google Drive que usa a função IMPORTXML para capturar os dados dos artigos publicados na revista "Educação Gráfica".

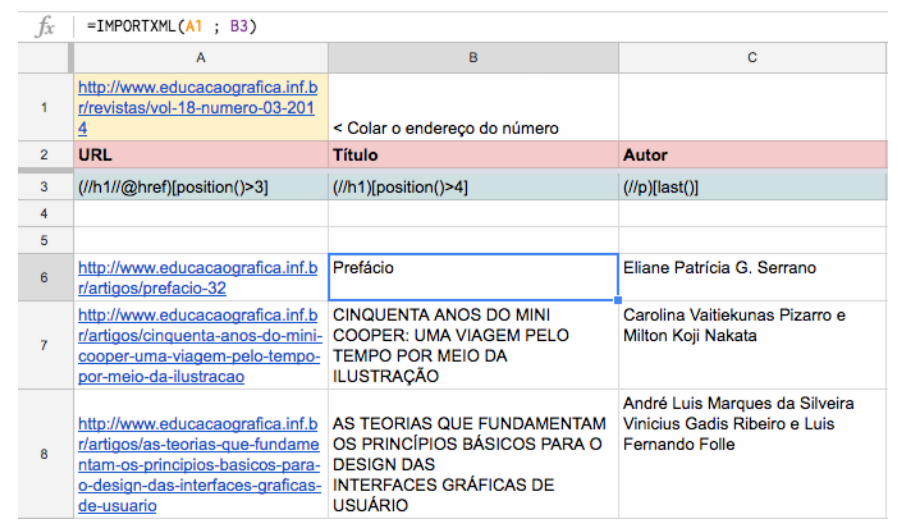

\section{Conclusão}

Como resultado, foi possível construir um panorama da produção científica da revista Educação Gráfica, tendo como produtos um banco de dados fundamental para pesquisas sobre desenho arquitetônico, uma análise bibliométrica baseada em parâmetros de co-citação e um procedimento técnico de levantamento e organização de dados que permitirá outros trabalhos de pesquisa bibliométrica, sendo possível traçar perfis da literatura na área de arquitetura.

\section{Agradecimentos}

Agradeço ao meu orientador, Daniel de Carvalho Moreira, pelo suporte e exemplo de dedicação no desenvolvimento do projeto.

Agradeço aos meus pais por todo amor e apoio.

Agradeço ao Pibic/Cnpq pelo fomento da pesquisa. 